Journal of Advanced College of Engineering and Management, Vol. 6, 2021

\title{
ANALYSIS OF GREENHOUSE GAS EMISSION FROM AIRCRAFTS AND GROUND SERVICE EQUIPMENT AT TRIBHUVAN INTERNATIONAL AIRPORT OF NEPAL
}

\author{
Ramesh Acharya ${ }^{1}$, Nawraj Bhattarai \\ ${ }^{1}$ Department of Applied Science, Institute of Engineering, Tribhuvan University, Pulchowk, Nepal \\ ${ }^{2}$ Department of Mechanical Engineering, Institute of Engineering, Tribhuvan University, Nepal \\ Corresponding Email: ${ }^{1}$ er.acharyaramesh@gmail.com, ${ }^{2}$ bnawaraj@gmail.com
}

\begin{abstract}
This paper highlights the trend of carbon dioxide emission and its reduction measure at Tribhuvan International Airport, which is the only international airport of Nepal. The landing and take-off (LTO) cycle of three-year (2016 to 2018) data were gathered from Civil Aviation Authority of Nepal (CAAN) for all types of aircrafts and fuel consumption data of each ground service equipment (GSE) were collected from Nepal Airlines Corporation (NAC). With the help of LTO emission factors published by different institutions and collected data, the emission was calculated and overall (international, domestic, helicopters and GSE) $\mathrm{CO}_{2}$ emission in the year 2016, 2017 and 2018 was found to be 56.55, 65.66 and 71.89 Kilotonnes respectively. Upon validation of calculated emission the discrepancy of $2.59 \%$ was found. The $\mathrm{CO}_{2}$ emission was forecasted up-to 2030 considering two scenarios namely, time series analysis and regression analysis. Lastly, for the $\mathrm{CO}_{2}$ reduction from GSE the scenario; Electrical GSE and Construction of Aerobridge was studied and from which it was found that the $\mathrm{CO}_{2}$ will be reduced by $80 \%$ if implemented.
\end{abstract}

Keywords: LTO, Aircrafts, GSE, Carbon dioxide, NAC, CAAN

\section{Introduction}

Nepal is a small landlocked mountainous country where there is only one international airport (Tribhuvan International Airport). Currently, above thirty international airlines link Nepal to destinations in Asia and the Middle East and the airport functions as a hub for several Nepalese airlines. The total contribution of aircraft emissions to total anthropogenic carbon dioxide $\left(\mathrm{CO}_{2}\right)$ emissions were considered to be about 2 percent in 1990 [1]. However, air traffic in the world is growing, and will likely continue to grow. Though, there is an improvement in the fuel efficiency of new aircraft, the long lifetime of aircraft and the expected growth in air traffic implies that this emission source in the future will increase in importance. Operation of aircrafts are usually divide into two main parts - the landing and takeoff cycle, and the cruise phase. The emission from aircraft varies during the different phases. The Taxi and Take-off phase of aircraft flight emits greater pollution than the landing phase.

- The Landing/Take-off (LTO) cycle includes all aircraft activities near the airport that take place below the altitude of 3000 feet $(1000 \mathrm{~m})$. Therefore, this includes taxi-in and out, take-off, climb-out, and approach and landing. Idle, approach, climb out and take-off are the four approaches of aircraft engine operation as defined by ICAO, which linked with a specific engine thrust setting and a time in mode.

- Cruise, which here is defined as all activities that take place at altitudes above 3000 feet $(1000 \mathrm{~m})$. No upper limit of altitude is given. In the inventory methodology, Cruise includes climb to cruise altitude, cruise, and descent from cruise altitudes.

TIA has been divided into two terminals, one for domestic flights and the other one for international flights, and has a terminal for VIP guests. The airport has just one runway, so it cannot afford to accommodate all the flights flying in and out. The TIA has a $10,000 \mathrm{ft}$. by $150 \mathrm{ft}$. runway dimension, which can handle 9 International Medium and Wide Body (for WB only 3 parking bay) Category 
Aircraft, 17 small aircrafts, and 13 helicopters. The aircraft used by air carriers, all twin engines are divided into four categories: turboprops, regional jets, narrow-body jets and wide-body jets. General description of each types of aircrafts is explaining as in given Table 1 [2].

Table 1: Aircrafts category and characteristics landed at TIA

\begin{tabular}{|l|l|l|}
\hline \multicolumn{2}{|l|}{ Aircraft category } & Characteristics \\
\hline \multirow{2}{*}{$\begin{array}{l}\text { Domestic } \\
\text { Aircrafts }\end{array}$} & Turboprop (TP) & 19-30 Passengers; 25,000 feet cruising altitude \\
\cline { 2 - 3 } & Regional Jet (RJ) & 37-90 Passengers; 37,000-42,000 feet cruising altitude \\
\hline $\begin{array}{l}\text { International } \\
\text { Aircrafts }\end{array}$ & Narrow-Body (NB) & 123-235 passengers; 37,000-42,000 feet cruising altitude \\
\cline { 2 - 3 } & Wide-Body (WB) & 250-400 passengers; 35,000 feet cruising altitude \\
\hline \multirow{3}{*}{ Helicopters } & Single & 3.5k lbs. can lift \\
\cline { 2 - 3 } & Twin Medium & 7-12.5k lbs. can lift \\
\hline
\end{tabular}

An airport inventory of GHG emissions, indeed, can allow identifying the sources and annual quantity of emissions, as well as the ownership for avoiding double counting when aggregate inventories are conducting at a regional or industry level. In this view, an inventory of greenhouse gases can become the benchmark against which to measure the achievement of quantitative targets set at the political level in the fight against climate change.

\section{Methodology}

\subsection{GHG Emissions Estimation Methodology}

The LTO emission factors as defined in Table 2 [3] [4] is taken as the basis for calculation of carbon dioxide emission from international aircrafts, domestic aircrafts and helicopters.

Table 2: LTO Emission factor for aircrafts

\begin{tabular}{|c|c|c|c|c|c|c|}
\hline \multirow{2}{*}{ S.N. } & \multirow{2}{*}{$\begin{array}{c}\text { Generic } \\
\text { Aircraft type }\end{array}$} & $\mathrm{CO} \square$ & $\mathrm{CH}_{4}$ & $\mathbf{N}_{2} \mathbf{O}$ & FUEL Consumption & \multirow{2}{*}{ Remarks } \\
\hline & & \multicolumn{4}{|c|}{ (Kg/LTO) } & \\
\hline 1 & A 310 & 4760 & 0.63 & 0.2 & 1510 & \multirow{11}{*}{$\begin{array}{c}\text { International } \\
\text { Aircrafts }\end{array}$} \\
\hline 2 & A319 & 2310 & 0.06 & 0.1 & 730 & \\
\hline 3 & $\mathrm{~A} 320$ & 2440 & 0.06 & 0.1 & 770 & \\
\hline 4 & A 321 & 3020 & 0.14 & 0.1 & 960 & \\
\hline 5 & A $330-200 / 300$ & 7050 & 0.13 & 0.2 & 2230 & \\
\hline 6 & $737-700$ & 2460 & 0.09 & 0.1 & 780 & \\
\hline 7 & $737-800 / 900$ & 2780 & 0.07 & 0.1 & 880 & \\
\hline 8 & $757-200$ & 4320 & 0.02 & 0.1 & 1370 & \\
\hline 9 & $767-300$ & 5610 & 0.12 & 0.2 & 1780 & \\
\hline 10 & $777-200 / 300$ & 8100 & 0.07 & 0.3 & 2560 & \\
\hline 11 & DHC8-100 & 640 & 0.00 & 0.02 & 200 & \\
\hline
\end{tabular}




\begin{tabular}{|c|c|c|c|c|c|c|}
\hline \multirow{2}{*}{ S.N. } & \multirow{2}{*}{$\begin{array}{c}\text { Generic } \\
\text { Aircraft type }\end{array}$} & $\mathbf{C O} \square$ & $\mathrm{CH}_{4}$ & $\mathbf{N}_{2} \mathbf{O}$ & FUEL Consumption & \multirow{3}{*}{ Remarks } \\
\hline & & \multicolumn{4}{|c|}{ (Kg/LTO) } & \\
\hline 12 & ATR72-500 & 620 & 0.03 & 0.02 & 200 & \\
\hline 13 & Turboprop & 230 & 0.06 & 0.01 & 70 & \multirow{2}{*}{$\begin{array}{l}\text { Domestic } \\
\text { Aircrafts }\end{array}$} \\
\hline 14 & Regional Jet & 620 & 0.03 & 0.02 & 200 & \\
\hline 15 & $\begin{array}{c}\text { Single } \\
\text { Helicopter Type }\end{array}$ & 80.145 & 0.005 & 0.005 & 25.995 & \multirow{2}{*}{ Helicopters } \\
\hline 16 & $\begin{array}{l}\text { Twin Medium } \\
\text { Helicopter Type }\end{array}$ & 188.018 & 0.014 & 0.014 & 60.985 & \\
\hline
\end{tabular}

\subsubsection{Ground Service Equipment}

Emission factors from GSE for carbon dioxide is taken as 3150 gram $/ \mathrm{Kg}$ of diesel [5] because aircrafthandling equipment varies by state, airport and aircraft operator, an analysis should be perform using emission factors appropriate for the GSE fleet being assessed.

\subsection{Forecasting Methodology}

\subsubsection{Scenario 1: Time Series Analysis}

Time series analysis is a statistical technique that deals with time series data, or trend analysis. Time series data means that data is in a series of particular time periods or intervals. The moving averages technique each observation is weighted equally. The six months moving average time series is used to forecast the Helicopter, Domestic and International LTO whereas the 52 weeks moving average is used for GSE. For example, a moving average of four observations would be:

$$
\mathrm{Yt}+1=(\mathrm{Y}(\mathrm{t}-3)+\mathrm{Y}(\mathrm{t}-2)+\mathrm{Y}(\mathrm{t}-1)+\mathrm{Yt}) / 4 \ldots \ldots \ldots \ldots \ldots \ldots \ldots . . . \mathrm{Eq} .1
$$

\subsubsection{Scenario 2: Regression Analysis}

The regression analysis is by far the most popular method of forecasting civil aviation demand. In regression analysis, the forecast is based not only on the historical values of the item being forecast but also on other variables that are considered to have a causal relationship. The historical data of 10 years from 2009-2018 was used to forecast the LTO cycle of domestic and international aircrafts along with diesel consumption by GSE. These forecasts are again used to forecast carbon dioxide emission. The main parameters contributing for the forecasting of carbon dioxide emission are International LTO Cycle, Domestic LTO Cycle, Tourist Arrival via Airway Count, Domestic Passengers Count, International Passenger Count, and Diesel Consumption by GSE. Forecasting of carbon dioxide emission from International aircrafts, Domestic aircrafts and GSE using regression analysis technique are explained below.

\subsubsection{International Aircraft}

Assumptions: The international passenger increases by $4.8 \%$ which is compounded annually [6]. And the tourists coming to Nepal in the year 2030 will be two million [7].

Calculation: The equation (from regression analysis) between international passenger and tourist count with no. of LTO cycle is obtain as follows.

$$
\mathrm{Y}=0.0041 \mathrm{x}_{1}-0.0003 \mathrm{x}_{2}-142.6844 \ldots \ldots \ldots \ldots \text {... } 2
$$


Where, $y=$ No.of international LTO cycle; $x_{1}=$ No.of international passenger; $x_{2}=$ No. of tourist count by air

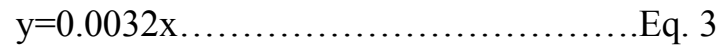

Where, $y=$ Carbon dioxide in kilotonnes; $x \_1=$ No.of internatinalLTO cycle

\subsubsection{Domestic Aircraft}

Assumptions: The tourists coming to Nepal in the year 2030 will be two Million [7].

Calculation: The equation (from regression analysis) between domestic passenger and tourist count with no. of LTO cycle.

$$
\mathrm{y}=0.002 \mathrm{x} \_1+0.011 \mathrm{x} \_2+27411.645 \ldots \ldots \ldots . . . \text { Eq. } 4
$$

Where, $y=$ No.of domestic LTO cycle; $x_{1}=$ No.of domestic passenger; $x_{2}=$ No.of tourist count by air

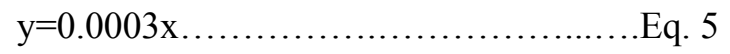

Where, $y=$ Carbon dioxide in kilotonnes; $x \_1=$ No.of domestic LTO cycle

\subsubsection{Ground Service Equipment}

Assumptions: As per the aforementioned calculation of no. of LTO cycle of international aircraft.

Calculation: The equation (from regression analysis) between diesel consumption by GSE and no. of international aircraft of LTO cycle.

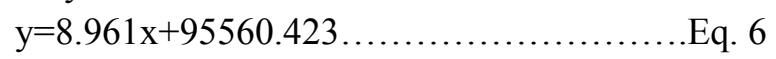

Where, $y=$ Diesel consumption by GSE; $x=$ No.international LTO cycle (forecasted)

\subsection{Carbon Dioxide Emission Reduction Methodology}

Among different reduction techniques Air Traffic Management, Reduction in the use of APU, Construction of Aerobridge, Policy for LTO emissions charges, Use of Dispatch towing, Airport Carbon Accreditation and Use of Electric Powered GSE here, I have chosen two-reduction technique i.e. construction of Aerobridge and use of electric powered GSE as scenario-3.

\subsubsection{Scenario 3: Electrical GSE and Construction of Aerobridge}

To reduce the consumption of diesel fuel by GSE this scenario was consider which will minimize carbon dioxide emission. In this case, the carbon dioxide emission reduction was calculated by replacing diesel equipment by electric GSE and attaching Ground Power Unit (GPU) and Air Conditioning Unit with Aerobridge. The available electric GSE in the world market are Baggage Tow Tractor, Conveyor Belt Loader, Lavatory Truck, Potable Water Truck and Forklift.

\section{Results and Discussions}

\subsection{Emission from Various Aircrafts}

Overall, it is evident that the Twin Medium Helicopter Type emitted higher amount of $\mathrm{CO}_{2}$ in each year whereas $\mathrm{N}_{2} \mathrm{O}$ and $\mathrm{CH}_{4}$ were discharged lesser by Single Helicopter Type. 


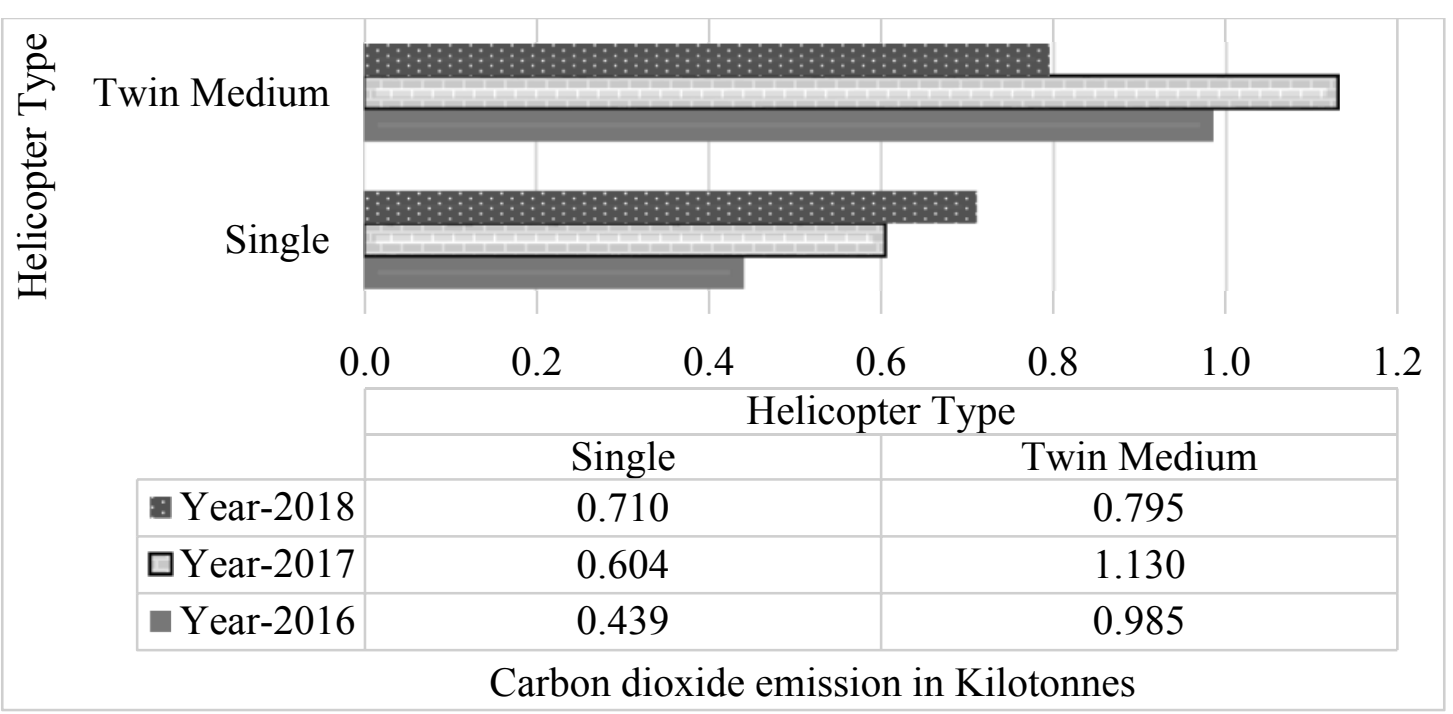

Figure 1: Carbon dioxide emission from two types of helicopters in the years 2016, 2017 and 2018

The tonne of CO released by second types of helicopter in the year 2016 was 98.93 which was twice and almost a quarter times higher than that of first type helicopter i.e. Single Helicopter Type which is show in figure 1. The $\mathrm{CO}_{2}$ emission by Twin Medium helicopter increased in next year and again decreased in the last year. Similarly, $\mathrm{N}_{2} \mathrm{O}$ and $\mathrm{CH}_{4}$ was exhausted by Single Helicopter in the same pattern. On the other hand, the $\mathrm{N}_{2} \mathrm{O}$ and $\mathrm{CH}_{4}$ emitted from Single Helicopter was viewed low at the beginning of the year and trend was slightly increasing. The $\mathrm{CO}_{2}$ emission by Single Helicopter in the last year was around twice times higher than that of starting year.

The line graph figure 2 explains the $\mathrm{CO}_{2}$ emissions at TIA within three years 2016, 2017 and 2018. The $\mathrm{CO}_{2}$ emission in the year 2016 by Turboprop aircrafts at TIA found 3.45 Kilotonnes whereas by Regional Jet aircrafts, is found 6.18 Kilotonnes around two times higher. However, in year 2018, the deviation between Turboprop and Regional Jet aircrafts seems four times higher which clearly represents the operation of Turboprop aircrafts is decreasing. Furthermore, the $\mathrm{CO}_{2}$ emission from Regional Jet aircrafts in the year 2018 increased two times than that of 2016. Overall, the $\mathrm{CO}_{2}$ emission increased gradually throughout the observation period.

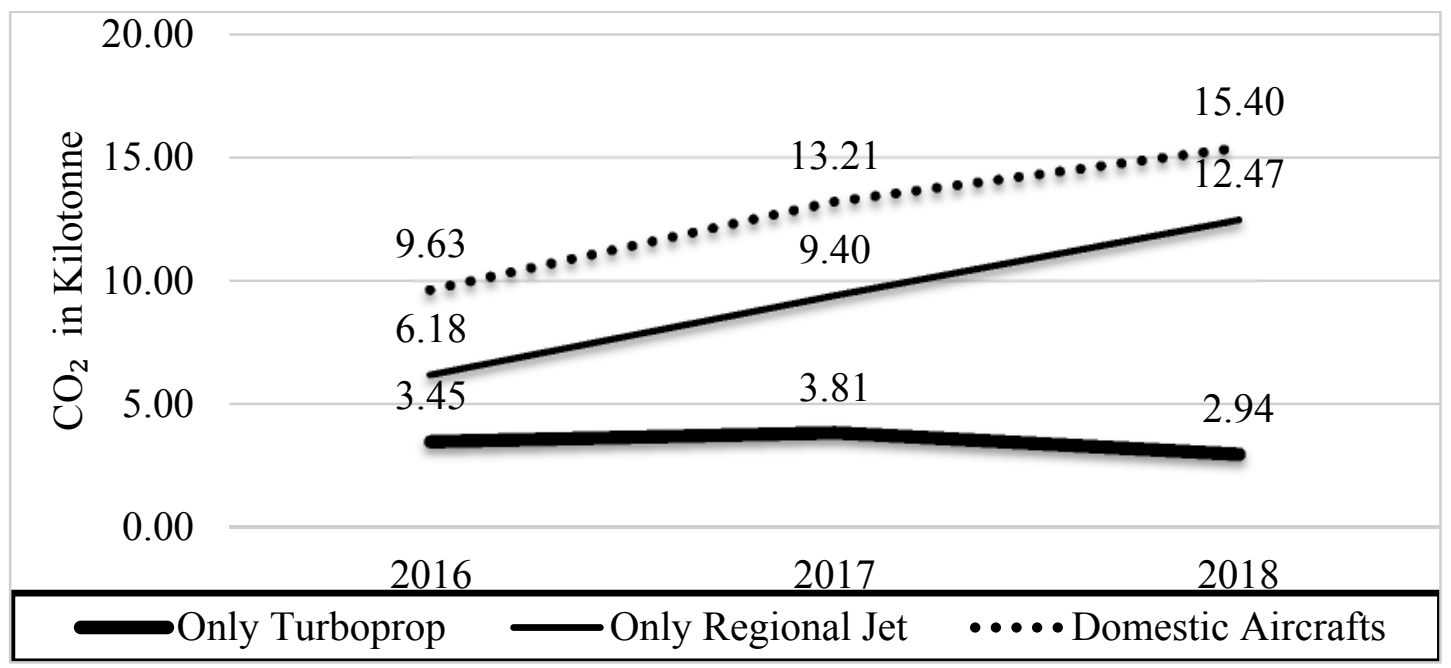

Figure 2: CO emitted by domestic aircrafts at TIA in 2016, 2017 and 2018 


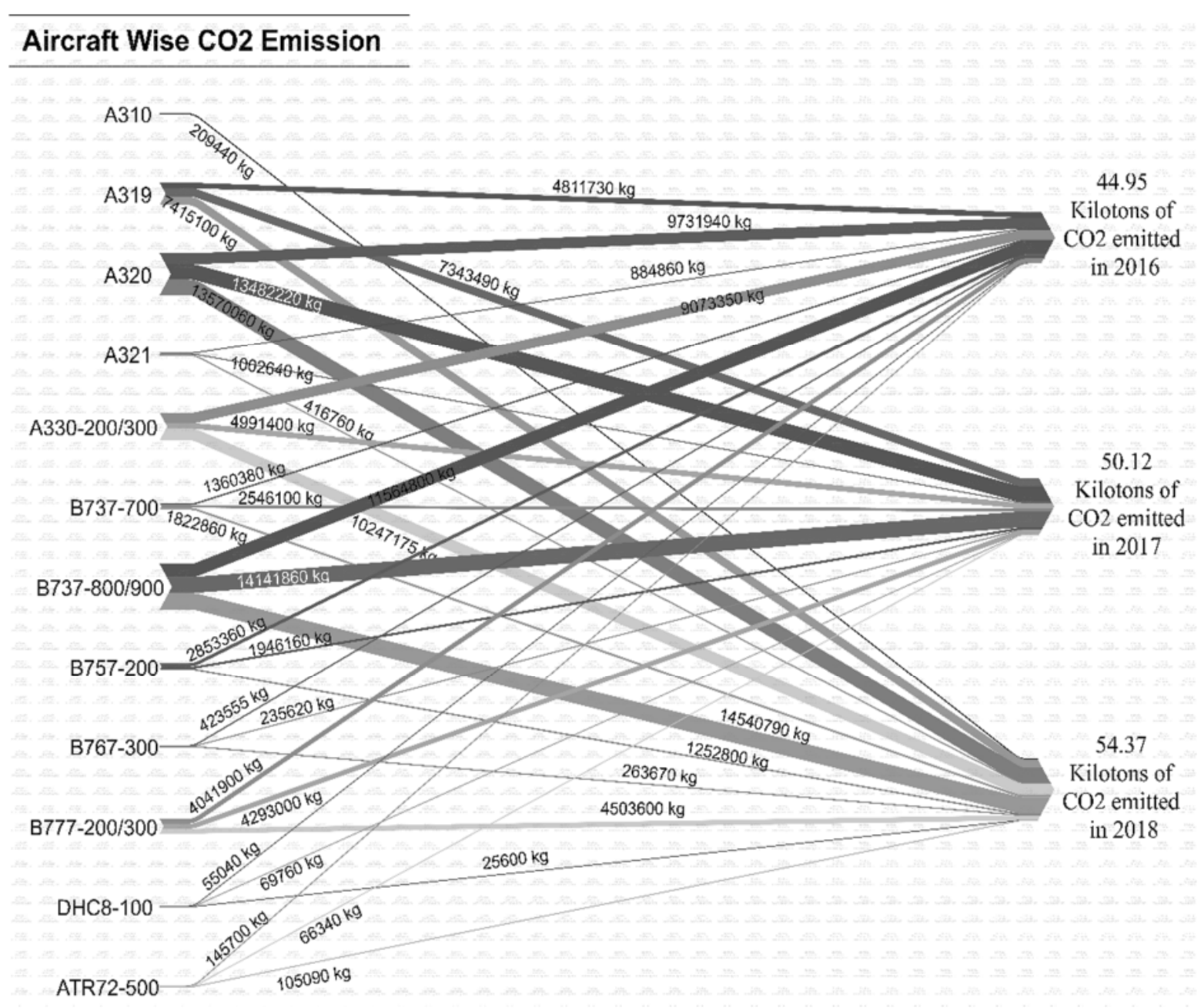

Figure 3: $\mathrm{CO}_{2}$ emitted by international aircrafts at TIA in 2016, $2017 \& 2018$

Figure 3 Sankey diagram illustrates the emission of $\mathrm{CO}_{2}$ from different type of aircrafts in the year 2016, 2017 and 2018. Within the observation period, the $\mathrm{CO}_{2}$ emission was prominently increased. As the emission from 2016 to 2017 was seen higher compared to year 2017 and 2018 . The most noticeable aircrafts emitting $\mathrm{CO}_{2}$ at TIA are A320 and B737. The major contributors for emission at TIA are commercial Passenger aircrafts (short haul flight). 


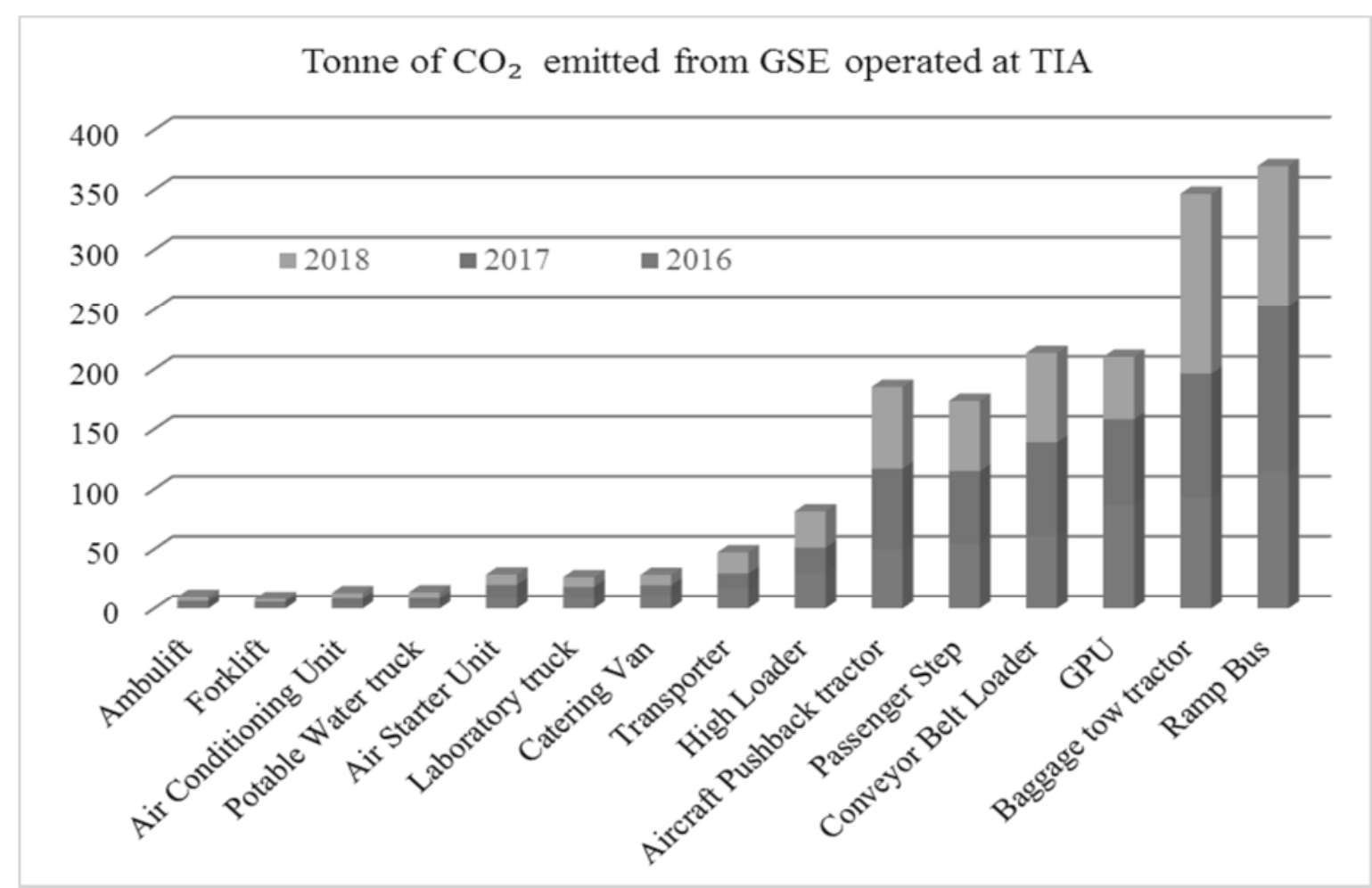

Figure 4: Cumulative tonnes of $\mathrm{CO}_{2}$ emitted by each GSE in three year

Figure 4 clearly depicts that the emission of $\mathrm{CO}_{2}$ from Ramp Bus was higher compared to other GSE and $\mathrm{CO}_{2}$ emitted by Baggage tow tractor in the year 2018 noted higher compared to other years.

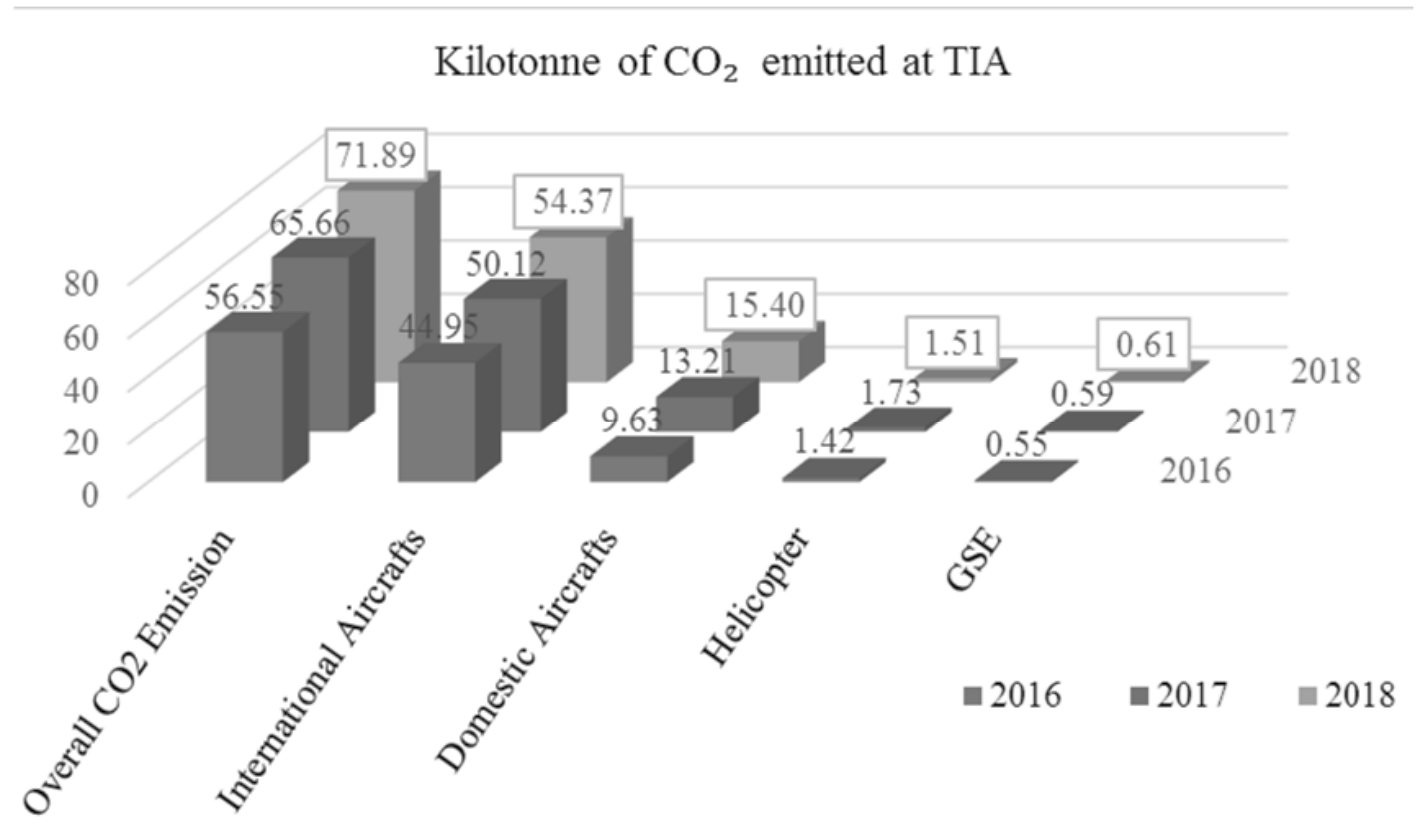

Figure 5: Contribution of $\mathrm{CO}_{2}$ emission by different sectors at TIA

The bar chart shown in Figure 5 illustrates the kilotonnes of $\mathrm{CO}_{2}$ emitted at TIA by international Aircrafts, Domestic Aircrafts, GSE and Helicopters in the year 2016, 2017 and 2018. Overall $\mathrm{CO}_{2}$ emission in the year 2016, 2017 and 2018 was found to be 56.55, 65.66 and 71.89 Kilotonnes respectively. It can be seen that the highest contributors of $\mathrm{CO}_{2}$ emission was international aircrafts 
throughout the year while, the lowest contributor was from Helicopters. Furthermore, a significant increase in emission by every sectors was observed over the period. The emission from domestic aircrafts has raised dramatically compared to other sectors. On the other hand, the amount of $\mathrm{CO}_{2}$ emission was slowly increasing in case of ground service equipment and helicopters. Analyzing, the $\mathrm{CO}_{2}$ emission, it was noted that each sectors are contributing in different increasing trend over the observation period.

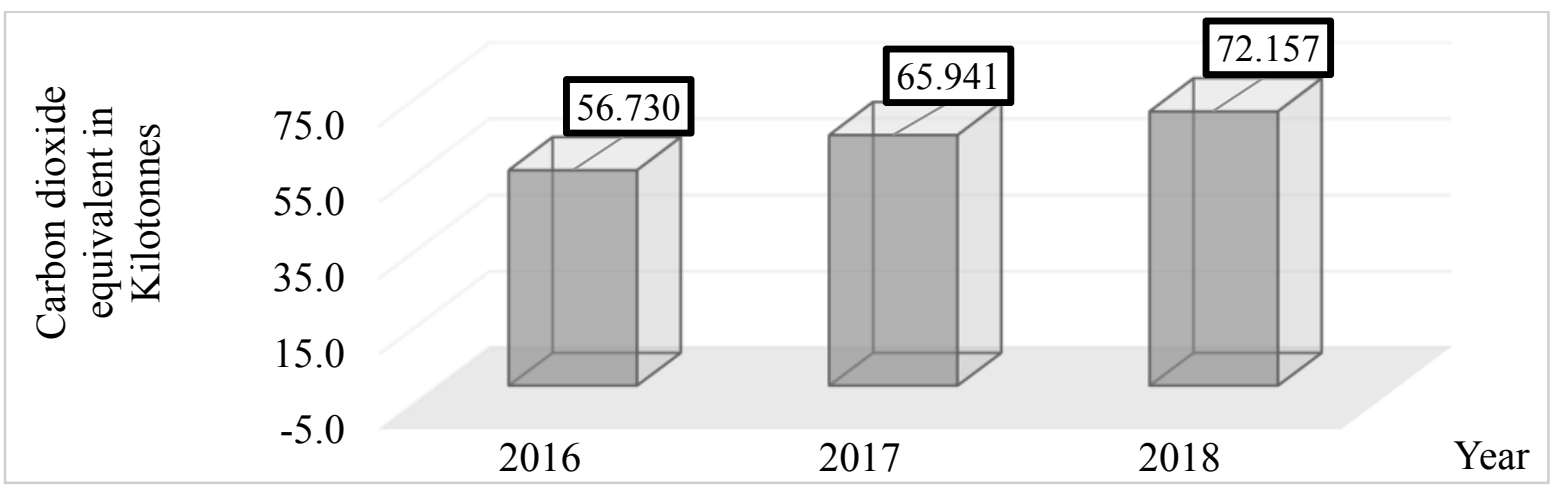

Figure 6: Carbon dioxide equivalent emitted at TIA

The carbon dioxide equivalent in 100-year time horizon is enumerating in the Figure 6 considering GWP for methane and nitrogen dioxide as 25 and 298 respectively including the emission from international aircrafts, domestic aircrafts and helicopters only. The methane and nitrogen dioxide emission from ground service equipment were excluded while calculating $\mathrm{CO} \square$ e. The $\mathrm{CO} \square$ equivalent emission was found to be 56.730, 65.941 and 72.157 kilotons for the respective year of 2016, 2017 and 2018. The incremental rate of the $\mathrm{CO} \square$ equivalent emission from year 2016 to 2017 was found to be $16.23 \%$ while from year 2017 to 2018 was found to be $9.42 \%$. The lower incremental rate on 2018 was due to the lower increment of passenger movement on the aircraft in 2018.

\section{2 $\quad$ Forecasting Results}

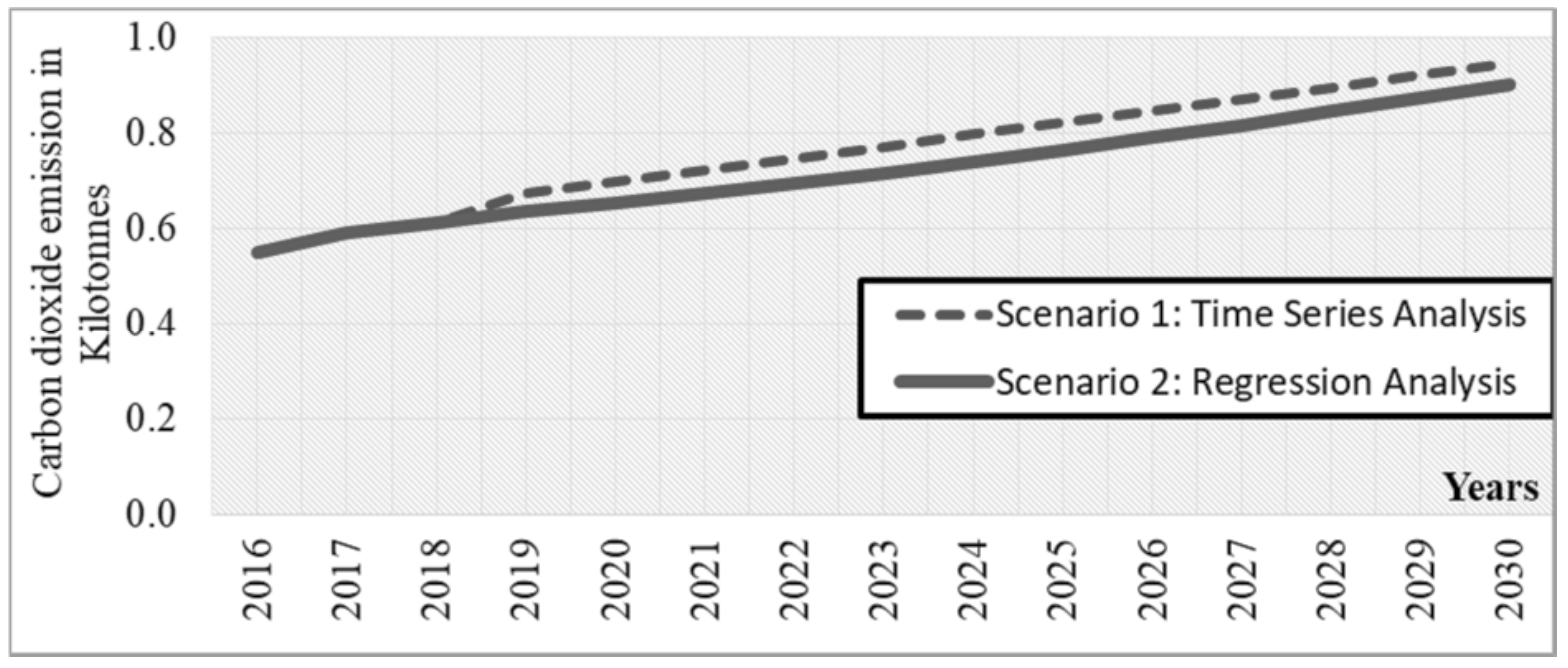

Figure 7: Forecasting of $\mathrm{CO}_{2}$ emission from GSE in Scenario 1\&2

The line diagram Figure 7 enumerates the forecasting of carbon dioxide emission up-to 2030 by ground service equipment in both the scenarios i.e. time series analysis and regression analysis and both analysis resulted similar trend. 


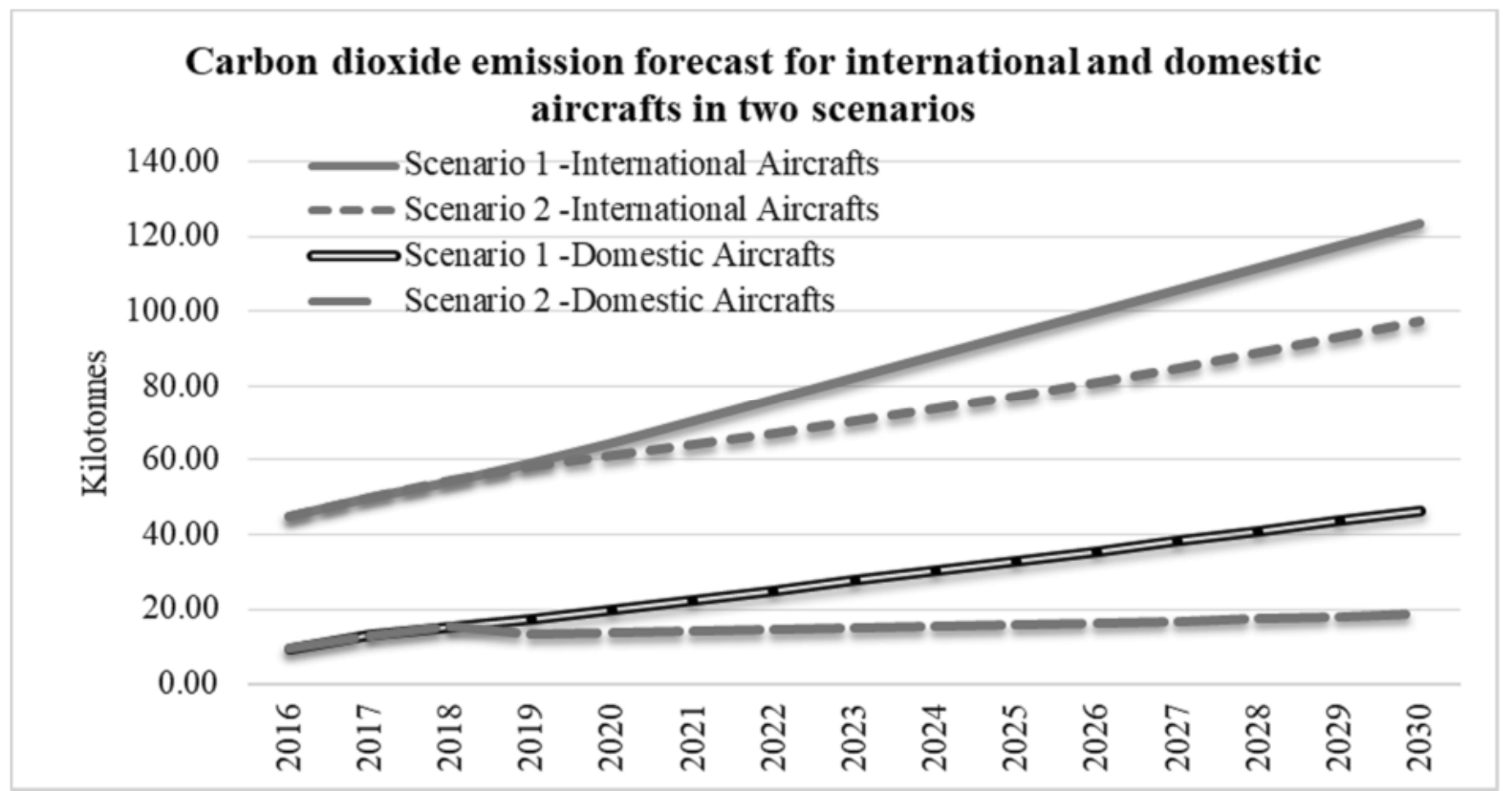

Figure 8: Comparison of $\mathrm{CO}_{2}$ emission from domestic and international aircrafts in both the scenarios

The line diagram Figure 8 depicts the forecasting of carbon dioxide emission up-to 2030 by international and domestic aircrafts in both the scenarios i.e. time series analysis and regression analysis. In time series analysis the carbon dioxide emission by international aircrafts in 2030 was forecasted 123.56 Kilotonnes whereas by regression analysis it was forecasted 97.43 Kilotonnes. Similarly, by domestic aircrafts the carbon dioxide emission in scenario 1 were forecasted 46.55 Kilotonnes.

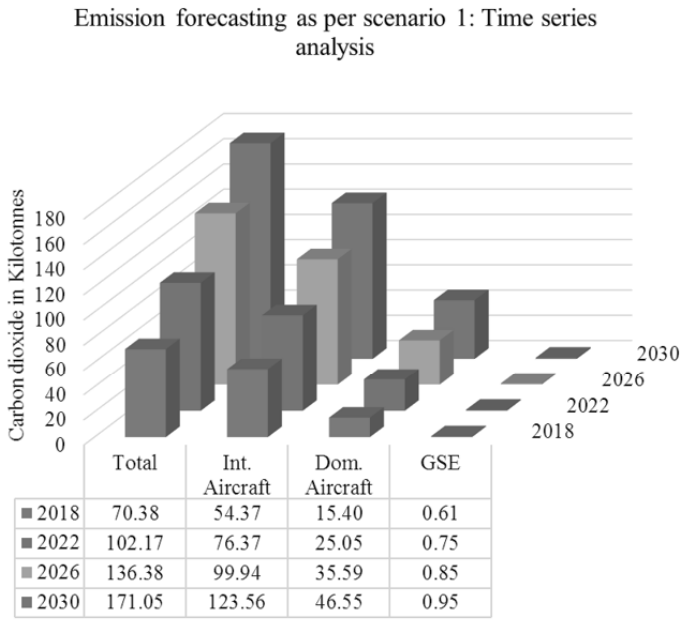

Figure 8 Scenario 1 forecasted $\mathrm{CO}_{2}$ emission by three sectors.
Emission forecasting as per scenario 2: Regression analysis

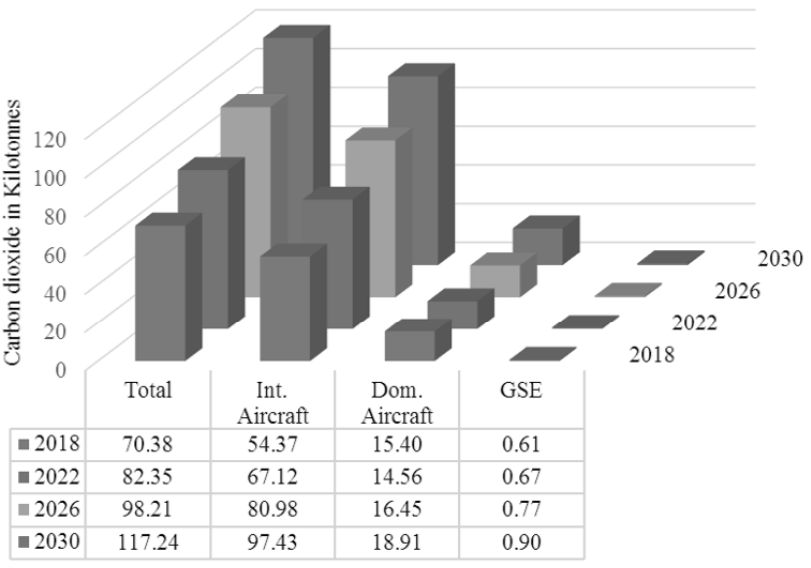

Figure 9 Scenario 2 forecasted $\mathrm{CO}_{2}$ emission by three sectors.

The figure 8 and figure 9 Error! Reference source not found. show the carbon dioxide emission in Kilotonnes forecasted in different years as per scenario 1: time series analysis and scenario 2: regression analysis. 
$\mathrm{CO}_{2}$ emission in base year 2018 and in 2030 with two scenarios

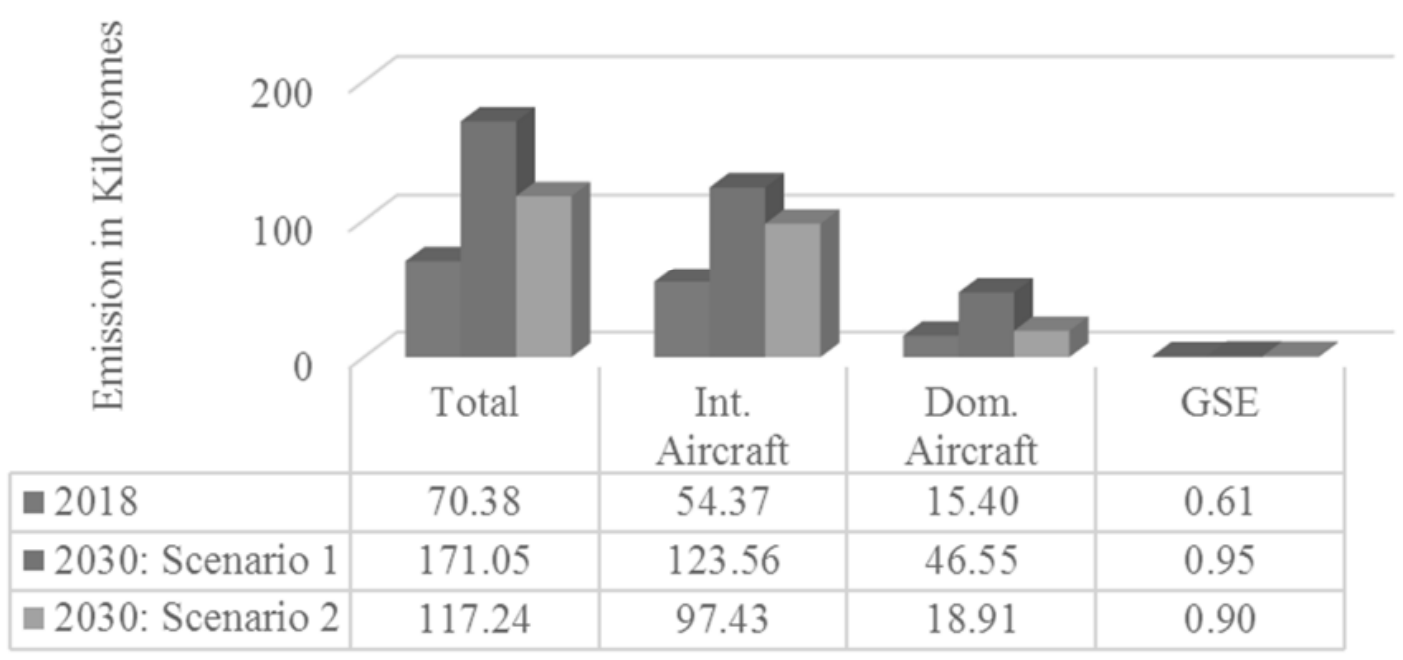

Figure 10:Total carbon dioxide emission in base year and in 2030 with two scenarios

The figure 10 enumerates the projection of carbon dioxide emission in 2030 at TIA with two different scenarios namely, time series analysis scenario and regression analysis scenario. Overall, the total carbon dioxide emission in 2030 will be more than twice higher than of 2018 in both the scenarios.

\subsection{Reduction Results}

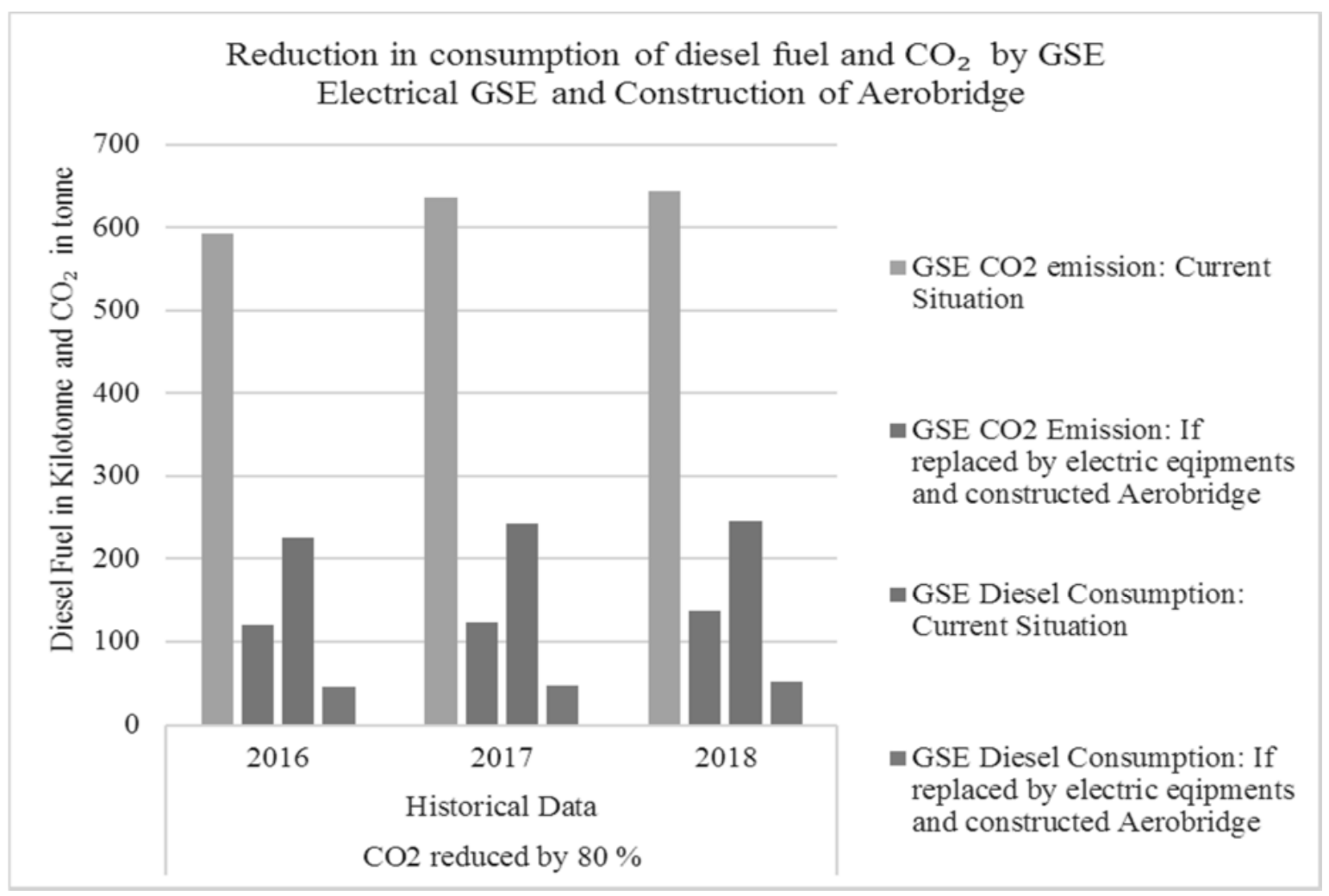

Figure 11: Reduction of $\mathrm{CO}_{2}$ by constructing Aerobridge and replacing diesel powered GSE by electric 
By replacing diesel equipment with electric powdered GSE and aerobridge mounted GPU and Air Conditioning Unit, we can reduce carbon dioxide emission by $80 \%$. The figure 11 shows the reduction in emission in 2016, 2017 and 2018 if such provision were adopted previously.

\subsection{Validation of emission per LTO cycle of Aircraft A320}

The time taken by aircraft A320 and fuel consumed to complete one LTO cycle data were collected from the website https://www.flightradar24.comand Nepal Airlines Corporation respectively as illustrated in table 3 .

Table 3: Actual data for the consumption of fuel by aircraft A320

\begin{tabular}{|c|c|c|c|c|c|}
\hline S.N. & Flight Status & Activity & $\begin{array}{l}\text { Time (UTC) } \\
\text { (HH:MM) }\end{array}$ & $\begin{array}{l}\text { Fuel indication } \\
(\mathrm{Kg})\end{array}$ & $\begin{array}{l}\text { Altitude } \\
\text { (ft.) }\end{array}$ \\
\hline 1 & \multirow{3}{*}{$\begin{array}{l}\text { During Takeoff (KTM- } \\
\text { BKK) }\end{array}$} & $\begin{array}{l}\text { Engine } \\
\text { Start }\end{array}$ & $05: 43$ & 10580 & 4390 \\
\hline 2 & & Approach & 05:50 & - & 4390 \\
\hline 3 & & Takeoff & $05: 57$ & 9910 & 7350 \\
\hline 4 & \multirow{2}{*}{$\begin{array}{l}\text { During Landing (DEL- } \\
\text { KTM) }\end{array}$} & Descent & $07: 25$ & 3310 & 7400 \\
\hline 5 & & $\begin{array}{l}\text { Engine } \\
\text { Stop }\end{array}$ & 07:31 & 3230 & 4390 \\
\hline \multicolumn{4}{|c|}{ Actual fuel consumed to complete one LTO cycle at TIA by A320 } & 750 & \\
\hline \multicolumn{4}{|c|}{ LTO cycle fuel consumption factor provided by IPCC for A320 } & 770 & \\
\hline
\end{tabular}

As per emission factor per LTO cycle provided by IPCC,

$770 \mathrm{Kg}$ of fuel consumed by $\mathrm{A320}=2440 \mathrm{~kg}$ of $\mathrm{CO}_{2}$ emission

$$
\begin{aligned}
& 750 \mathrm{Kg} \text { of fuel consumed by } \mathrm{A} 320=\frac{2440}{770} \times 750 \\
&=2376.6 \mathrm{~kg} \text { of } \mathrm{CO}_{2} \text { emission } \\
& \text { Difference }=\frac{2440-2376.6}{2440} \times 100 \\
&=2.59 \% \text { lower }
\end{aligned}
$$

\section{Conclusions}

Among international aircraft, domestic aircraft, helicopter and GSE, GSE are the least polluters which consumes $0.91 \%$ of total fuel consumed in the year 2018 whereas the international aircrafts were found to be one of the major polluters. Overall $\mathrm{CO} \square$ emission from all sources were found to be $56.55,65.66$ and 71.89 Kilotonne in the year 2016, 2017 and 2018 respectively because of significant increase in emission from each and every sector. Among aircrafts, international aircrafts were higher contributor while helicopters were the lowest contributor of $\mathrm{CO} 2$ emission throughout the analysis period. The overall $\mathrm{CO} \square$ equivalent emissions were found to be $56.730,65.941$ and 72.157 kilotons for the year of 2016, 2017 and 2018 respectively. 
After forecasting the overall $\mathrm{CO} \square$ emission; in time series analysis, it was found that the emission is more than twice higher than that of base year 2018 whereas using regression analysis it was nearly about two times higher.

Upon validation of the obtained result by considering Airbus A320 for the flight to Kathmandu to Bangkok and Delhi Kathmandu the calculated equivalent fuel consumption during LTO cycle was found to be $750 \mathrm{~kg}$ while according to IPCC report the equivalent fuel consumption during similar period is reported to be $770 \mathrm{~kg}$ showing the discrepancy of $2.59 \%$ in $\mathrm{CO} \square$ emission.

Although the share of emission from GSE is very low, the carbon dioxide emission was 0.61 Kilotonnes in 2018. Upon scrutinizing the reduction techniques, it is found that replacing diesel equipment with electric GSE (Baggage Tow Tractor, Conveyor Belt Loader, Lavatory Truck, Potable Water Truck and Forklift) and using aerobridge mounted Ground Power Unit and Air Conditioning Unit, the carbon dioxide emission were reduced by $80 \%$.

\section{Recommendations}

Studying the historical and forecasted LTO cycle for international aircraft, current parking bay with effective utilization (considering minimum turnaround time) can hold the flow of aircraft up-to 2030 so, it is recommended to construct the passenger boarding bridge in existing parking bays for the reduction of carbon dioxide emission. It is recommended to focus on air traffic management system, reduction in the use of APU, construction of Aerobridge, policy for LTO emission charges, use of dispatch towing equipment, follow airport carbon accreditation and replace the GSE by electric powered GSE. It is recommended for ground handling organization at TIA to procure electrical ground service equipment.

\section{References}

1. Brandon M. Graver, H. C. F., 2009. “Estimation of Air Carrier Emissions at Raleigh-Durham International Airport”, Durham: Air \& Waste Mangement Association.

2. D.J. Wuebbles, M. L. G. M. K., 2007. “Evlauating the Impact of Aviation on Climate Change. “ ResearchGate, p. 4.

3. Dessens, O. et al., 2014. "Aviation and Climate Change."

4. IATA/Tourism Economics, 2018. “The global air transport industry.” s.1.:IATA.

5. IATA, 2018. “An Airline Handbook on CORSIA.” Third Edition ed. London: IATA.

6. ICAO, 2011. “Airport Air Quality Manual”, Montreal, Canada : ICAO.

7. IPCC, Working Group I,II\&III, 1990. “First Assessment Report of IPCC”, Geneva: Cambridge University Press.

8. IPCC, 2006. Chapter 3 Mobile Combustion. In: “Guidelines for National Greenhouse Gas Inventories.” s.1.:s.n., pp. 3.1-3.78.

9. Rypdal, K., 2000. “Aircraft Emission”, Norway: s.n.

10. SR, S., BR, U. \& K, a. P., 2012.”Nepal 2030: A Vision for Peaceful and Prosperous Nation”, s.1.: South Asia Regional Coordination Office of the Swiss National Centre of Competence in Research (NCCR North-South) and Department of Development Studies, Kathmandu University.

11. Wilson, D. et al., 2014. Year 2011” Gulfwide Emissions Inventory Study”, New Orieans, LA: U.S. Department of the interior Bureau of Ocean Energy Management Gulf of Mexico OCS Region.

12. Winter, M. \& Rypdal, K., 2010. “EMEP/EEA Emission Inventory Guidebook 2009 (Updated)”, s.1.: EMEP/EEA. 